\title{
Tocilizumab: The evidence for its place in the treatment of juvenile idiopathic arthritis
}

This article was published in the following Dove Press journal:

Core Evidence

6 August 2009

Number of times this article has been viewed

\section{Troels Herlin}

Department of Pediatrics, Aarhus University Hospital, Skejby, Aarhus, Denmark
Correspondence: Troels Herlin Professor of Pediatric Rheumatology, Department of Pediatrics, Aarhus University Hospital, Skejby, DK-8200 Aarhus N Denmark

Tel +45-8949 6704

Fax +45-89496023

Email troeherl@rm.dk
Introduction: Juvenile idiopathic arthritis (JIA) is one of the most common chronic diseases with childhood onset. It comprises different subtypes of which the systemic onset subtype is often resistant to treatment. With the advent of biological treatment with tumor necrosis factor- $\alpha(\mathrm{TNF} \alpha)$-inhibitors, the clinical outcome of JIA has improved considerably, but only for subtypes other than systemic JIA. Substantial evidence shows that the proinflammatory cytokine interleukin-6 (IL-6) plays a pivotal role in systemic JIA. The blockage of IL-6 action by tocilizumab, a humanized anti-IL-6-receptor monoclonal antibody, could therefore be an effective treatment of systemic JIA.

Aims: The purpose of this article was to review the clinical trials of tocilizumab and to discuss its place in the treatment of JIA with the focus on the systemic onset of disease.

Evidence review: Two phase II studies and one phase III clinical trial of tocilizumab demonstrating the clinical efficacy and safety in systemic onset JIA have been published. Within those studies, sustained and high response rates of clinical improvement have been achieved with American College of Rheumatology Pediatric criteria (ACRPed) 30, 50, and 70 observed in $98 \%, 94 \%$, and $90 \%$ of patients, respectively, after 48 weeks. One study regarding the clinical efficacy of tocilizumab for the treatment of oligo- and polyarticular JIA has been presented only as a conference abstract.

Place in therapy: The very promising results seen so far in patients with severe systemic JIA and acceptable tolerability gives tocilizumab a central role in the future therapy in controlling this disease. No other biological therapy has achieved similar high response rates when treating with tocilizumab $8 \mathrm{mg} / \mathrm{kg}$ every two weeks to patients with systemic onset JIA, but direct comparison of the efficacy of different biological agents are not yet available.

Keywords: tocilizumab, anti-IL-6-receptor antibody, biologics, systemic, juvenile idiopathic arthritis

Core evidence place in therapy summary for tocilizumab in the treatment of juvenile idiopathic arthritis

\begin{tabular}{|c|c|c|}
\hline Outcome measure & Evidence & Implications \\
\hline $\begin{array}{l}\text { Patient-oriented evidence } \\
\text { Improvement of symptoms }\end{array}$ & Clear & $\begin{array}{l}\text { Reduction of joint pain and improvement } \\
\text { of joint motion }\end{array}$ \\
\hline Reduction of fever & Substantial & Rapid normalization of temperature \\
\hline Tolerability & Clear & Few infusion reactions \\
\hline Long-term safety & Limited & $\begin{array}{l}\text { Upper respiratory tract infections observed } \\
\text { but long-term observation are not at hand }\end{array}$ \\
\hline
\end{tabular}

(Continued) 


\begin{tabular}{|c|c|c|}
\hline \multicolumn{3}{|l|}{ (Continued) } \\
\hline Outcome measure & Evidence & Implications \\
\hline \multicolumn{3}{|l|}{ Disease-oriented evidence } \\
\hline Reduction in synovitis & Clear & $\begin{array}{l}\text { Improvement in number of swollen joints and } \\
\text { joints with limitation in motion }\end{array}$ \\
\hline Reduction of anemia & Clear & Rapid increase in hemoglobin \\
\hline Reduction of inflammatory response & Substantial & $\begin{array}{l}\text { Rapid decrease in CRP, ESR, neutrophils and } \\
\text { platelet count }\end{array}$ \\
\hline $\begin{array}{l}\text { Maintenance of response during } \\
\text { treatment }\end{array}$ & Clear & Long-term efficacy only during treatment \\
\hline \multicolumn{3}{|l|}{ Economic evidence } \\
\hline Cost effectiveness & Unclear & Long-term pharmacoeconomic studies missing \\
\hline
\end{tabular}

\section{Scopes, aims, and objectives}

Tocilizumab (Actemra ${ }^{\circledR}$, Chugai Pharmaceutical Co., Ltd. and F Hoffmann-La Roche) is a humanized anti-interleukin-6 (IL-6)-receptor antibody used in the targeted therapy of rheumatoid arthritis (RA) and juvenile idiopathic arthritis (JIA). Tocilizumab blocks the activity of the proinflammatory cytokine, IL-6, which exerts a central role in both diseases. Within recent years, tocilizumab has been used for RA patients with treatment-resistant disease. The aim of this article was to review the clinical trials of tocilizumab for the use in systemic onset JIA and to discuss its role in the treatment strategy for this disease.

\section{Methods}

A review of the medical literature regarding tocilizumab was performed. Articles related to tocilizumab on PubMed (http://www.ncbi.nlm.nih.gov) using the search terms "tocilizumab" (117), "tocilizumab AND juvenile idiopathic arthritis" (26), and "anti-IL-6-receptor blockade AND juvenile idiopathic arthritis" (9) were selected for the review. The search was updated on February 20, 2009. Articles not written in English were excluded. Furthermore, the search term "tocilizumab AND rheumatoid arthritis" (79) was used to review clinical trials on adult patients with RA. In addition, selected abstracts from the Annual Meetings of the American College of Rheumatology (ACR) and of the European League Against Rheumatism (EULAR) in 2007 and 2008 were used.

\section{Disease overview}

Juvenile idiopathic arthritis is a collective term for different patterns of arthritis of unknown cause in children. ${ }^{1}$ All of them are defined as chronic arthritis lasting for more than six weeks in the absence of any known cause in a child aged under 16 years. JIA is classified according to the onset of the disease into seven subtypes: systemic, persistent oligoarticular, extended oligoarticular, rheumatoid factor-positive polyarticular, rheumatoid factor-negative polyarticular, psoriatic, and enthesitis-related arthritis subtypes. The disease is among the most frequent chronic diseases starting in childhood and in population-based studies using the International League of Associations for Rheumatology (ILAR) criteria, an annual incidence of 14-15 per 100,000 has been reported. ${ }^{2,3}$

Systemic onset JIA, representing about $10 \%$ of JIA, is a subtype quite distinct from the other subtypes characterized by a quotidian, spiking fever lasting more than two weeks, nonfixed erythematous skin rash, generalized lymphadenopathy, hepatosplenomegaly, or serositis. ${ }^{4}$ Arthralgia and myalgia can be prominent during fever attacks. The arthritis, which may not be present during the early phase of the disease, is often presented as a symmetrical polyarticular arthritis. Marked increases in the acute phase reactants are observed resulting in at times very high levels of C-reactive protein (CRP) and erythrocyte sedimentation rate (ESR). Leukocytosis, predominantly neutrophils, is commonly observed, as well as thrombocytosis, which may reflect the exacerbations of the disease.

The course of systemic onset JIA can be monocyclic, polycyclic, or persisting with destructive arthritis. The overall outcome of the disease is poor with a high risk of long-term functional impairment. ${ }^{5} \mathrm{~A}$ severe, life-threatening complication to systemic onset JIA is macrophage activation syndrome, a secondary form of hemophagocytic lymphohistiocytosis, presented with prolonged fever, pancytopenia, elevated liver transaminases, coagulopathy, and high levels of triglycideride and ferritin. ${ }^{6}$ Furthermore, growth failure, osteoporosis, secondary amyloidosis are other severe complications of the disease. 


\section{The role of IL-6 in the pathogenesis of JIA}

Interleukin (IL)-6 is a $26 \mathrm{kD}$ glycoprotein consisting of 184 amino acids which has previously been assigned different names such as B-cell differentiation factor (BCDF), Interferon- $\beta 2$, a hybridoma/plastocytoma growth factor. Later, these names were replaced by IL- $6 .{ }^{7} \mathrm{IL}-6$ is produced by a variety of cells of which several participate during inflammation such as T- and B-cells, monocytes, fibroblasts, and endothelial cells.

Function of IL-6 is mediated through two membrane proteins, the membrane-bound IL-6R, an $80 \mathrm{kD}$ ligand-binding receptor, and gp130, a $130 \mathrm{kD}$ signal transducing element. In addition there is a soluble form of IL-6R present in serum. When binding to IL-6, both soluble and membrane IL-6R connects to gp 130 on the membrane whereby the intracellular signal activating the Jak-STAT pathway is mediated. ${ }^{8,9}$

During acute inflammation IL-6 stimulates hepatocytes to produce acute-phase proteins such as CRP, haptoglobin, fibrinogen, $\alpha 1$-antitrypsin, or serum amyloid A. IL-6 stimulates the production of hepcidin, an iron regulatory peptide hormone which reduces iron transport in the intestines and inhibits the release of iron from macrophages leading to anemia. Differentiation of osteoclasts is stimulated by IL-6 leading to joint destruction and osteoporosis.

Abnormal expression of the proinflammatory cytokines IL-1, IL-6, and tumor necrosis factor- $\alpha$ (TNF $\alpha)$ is seen in systemic JIA. It has been demonstrated by several studies that IL-6 is significantly elevated in the blood and synovial fluid of patients with systemic JIA. ${ }^{10-13}$ The level of IL-6 fluctuates with the characteristic spiking fever, which is not the case for the increased levels of TNF $\alpha$. The high levels of IL-6, also being responsible for the impaired growth, thrombocytosis and chronic anemia, lead to the suggestion that systemic JIA is a IL-6-mediated disease. ${ }^{14}$ IL-6 and IL-1RA, being induced by IL-6, correlates with systemic JIA disease activity, which is not the case for IL- 1 and TNF $\alpha .{ }^{15}$ IL-6 form complexes with its soluble receptor, sIL-6R, which trigger gp130 dimerisation and signaling. Also, elevated concentration of sIL-6R has been found during active disease. ${ }^{16}$

In family studies the $-174 \mathrm{G}$ allele of IL- 6 gene has been confirmed as a susceptibility gene for systemic JIA, since it correlates with higher levels of IL- $6 .{ }^{17,18}$

\section{Outcome measures}

The American College of Rheumatology Pediatric (ACRPed) criteria for the definition of improvement of the clinical outcome measures for JIA was proposed by Giannini and colleagues. ${ }^{19}$ A patient is considered to have responded to therapy (ACRPed30) if there is an improvement in at least three out of six variables (active joint count, number of joints with limited range of motion, parent/patient global assessment on a visual analogue scale, physician global assessment on a visual analogue scale, first hour ESR ( $\mathrm{mm} / \mathrm{hour}$ ), Childhood Health Assessment Questionnaire) by at least $30 \%$ and worsening in not more than one variable by more than $30 \%$ (Table 1). For the ACRPed50 and ACRPed70, an improvement of at least $50 \%$ or $70 \%$, respectively, must be achieved in three out of six of the above variables with worsening in not more than one variable by more than $30 \%$.

\section{Current therapeutic options}

Treatment of patients with systemic JIA remains a challenge. Many different treatment regimens with immunosuppressants have been used. Although corticosteroids have been the mainstay of therapy for children with active systemic JIA, there is no evidence that systemic corticosteroids are disease modifying. Due to unacceptable, deleterious long-term side effects such as growth retardation, osteoporosis, and diabetes, reduction of corticosteroid dosage and prevention of prolonged therapy is mandatory. Instead of high-dose daily oral corticosteroids pulses with high-dose intravenous methylprednisolon (up to $30 \mathrm{mg} / \mathrm{kg}$ per dose, maximal $1000 \mathrm{mg}$ have been proposed to minimize side effects. ${ }^{20}$ In a few patients, nonsteroidal anti-inflammatory drugs (NSAIDs) alone have been effective. More often methotrexate either given orally or subcutaneously have been used as a second-line medication in systemic JIA but has been less effective compared to the use in treating polyarticular JIA. ${ }^{21}$ Biological therapy with anti-TNF $\alpha$ agents have limited effect in systemic JIA with response rates as low as $30 \%{ }^{22,23}$ Pascual and colleagues ${ }^{24}$ demonstrated that sera from nine patients with systemic JIA provoked IL-1 synthesis

Table I Core set of criteria for evaluating change in treatment trials of children with juvenile idiopathic arthritis: American College of Rheumatology Pediatric response criteria ${ }^{19}$

I. Number of active joints (swollen joints and/or two or three of the following: limitation of range of motion, pain on motion, and increased heat of joints).

2. Number of joints with limited range of motion.

3. Physician global assessment of disease activity.

4. Patient/parent assessment of overall well being.

5. Functional ability (Childhood Health Assessment Questionnaire). 6. Erythrocyte sedimentation rate.

Notes: Improvement is at least $30 \%$ improvement from baseline in three of any six variables with no more than one of the remaining variables worsening by $>30 \%$. 
in tissue culture of mononuclear cells. In seven of these nine patients, treatment with anakinra, an anti-IL-1 receptor antagonist, gave a complete clinical response. In an open-label study, 20 patients with systemic JIA refractory to corticosteroids were treated with anakinra $1-2 \mathrm{mg} / \mathrm{kg} / \mathrm{day}$. Only moderate response rates were found with an ACRPed30, 50, and 70 of $55 \%, 30 \%$, and $0 \%$, respectively, after three months and after six months 50\%, 25\% and 10\%, respectively. ${ }^{25}$ A multicenter, randomized double-blind trial of anakinra versus placebo in systemic JIA with 12 patients in each group has been conducted and preliminary results were presented. ${ }^{26}$ Achievement of ACRPed30 response along with resolution of fever and normalization of CRP after one month was seen in 8/12 in the anakinra group compared to $1 / 12$ in the placebo group. Because daily subcutaneous injections are required and are painful, the practical use of anakinra has been limited. A long-acting soluble receptor-based IL-1 blocker, rilonacept (IL-1 Trap), has been investigated in a phase II trial in systemic JIA. Preliminary results published in abstract form from the open-label phase including 21 patients have revealed improvement after four weeks with ACRPed30, 50, and 70 responses of $76.2 \%, 61.9 \%$, and $33 \%$, respectively. ${ }^{27}$ Fever and/or rash was completely resolved. Sustained response was recorded in 12 patients. Treatment with rilonacept was generally safe and well tolerated.

\section{Tocilizumab}

The blockade of the biological functions of IL-6 may theoretically be available through a blockade of the gp130 receptor by neutralizing IL- 6 or by the prevention of the IL-6/IL-6R complex formation. Since the gp130 homodimer is shared among other receptors than for IL-6, the blockade of gp130 may implicate a wide range of undesirable effects. Attempts of trials with chimaeric anti-IL-6 monoclonal antibody have failed to block IL-6 function. ${ }^{28,29}$

Tocilizumab, formerly myeloma receptor antibody (MRA), is a humanized anti-IL-6R monoclonal antibody (humanized by the technique of complementary-determining region grafting from mouse anti-human IL-6R monoclonal antibody) engrafted with a human IgG1 Fc to minimize potential immunogenic responses in humans. ${ }^{30}$ It has a high affinity to IL-6R and abrogates the IL-6 signaling by preventing the formation of the IL-6/IL-6R complex.

The clinical efficacy of tocilizumab in preliminary studies has previously been described in murine experimental arthritis, ${ }^{31}$ in patients with RA, ${ }^{32-34}$ multicentric plasma cell type or mixed type Castleman's disease ${ }^{35}$ and adult-onset Still's disease. ${ }^{36}$

\section{Clinical efficacy of tocilizumab}

\section{in adults with RA}

Tocilizumab was launched in April 2008 in Japan and was approved by the European Agency for the Evaluation of Medicinal Products (EMEA) in January 2009 for the treatment of moderate and severe RA, but has not yet been approved by the US Food and Drug Administration (FDA). Results from randomized controlled trials of tocilizumab in RA are summarized in Table 1 . In the CHARISMA study, ${ }^{37}$ a phase II study evaluating the efficacy of tocilizumab in 359 patients with active RA and with an inadequate response to methotrexate, patients were randomized to seven study arms evaluating the effect of three doses of tocilizumab: 2, 4, and $8 \mathrm{mg} / \mathrm{kg}$ with or without methotrexate plus methotrexate alone. The infusion of tocilizumab was given at four-week intervals. ACR20 responses were achieved in all tocilizumab arms at doses of 4 and $8 \mathrm{mg} / \mathrm{kg}$ (Table 2).

Four phase III randomized, double-blind placebocontrolled trials evaluating the effect of tocilizumab versus placebo in a total of 2,467 patients with RA have been published since $2008 .^{38-41}$ In all studies with RA, tocilizumab was infused at four-week intervals. The most significant results were observed with doses of $8 \mathrm{mg} / \mathrm{kg}$ with achievement of ACR20 responses of 50\%-80.3\%, ACR50 responses of $29 \%-49 \%$, and ACR70 responses of $12.4 \%-29.5 \%$. Remission, defined as Disease Activity Score (DAS28) $<2.6$, were observed in $27 \%-43.1 \%$ of patients receiving $8 \mathrm{mg} / \mathrm{kg}$ doses compared with $7.6 \%-13 \%$ of patients receiving $4 \mathrm{mg} / \mathrm{kg}$ in the OPTION and RADIATE trials.

In the SAMURAI study, a randomized X-ray doubleblind controlled trial, Nishimoto and colleagues ${ }^{42}$ evaluated the ability of tocilizumab monotherapy against conventional DMARDs to inhibit progression of structural joint damage in RA patients. After 52 weeks, the tocilizumab group showed significantly less radiographic change in the van der Heijde score (modified Sharp score) (mean 2.3, 95\% confidence interval $[\mathrm{CI}]: 1.5-3.2 ; \mathrm{p}<0.01)$ compared to the DMARD group (mean 6.1, 95\% CI: 4.2-8.0; $\mathrm{p}<0.01$ ). Erosion score was 0.9 and joint space narrowing was 1.5 in the tocilizumab group versus 3.2 and 2.9 in the DMARD group, respectively.

\section{Clinical efficacy of tocilizumab in systemic onset JIA}

Two phase II studies of the blockade of IL-6 signaling using anti-IL-6 receptor antibody (MRA, tocilizumab) for systemic JIA suggested that it was a highly effective treatment. ${ }^{43,44}$ 
Table 2 Randomized controlled trials of tocilizumab in rheumatoid arthritis

\begin{tabular}{|c|c|c|c|c|c|c|c|c|c|}
\hline Trial name & Author & Design & $\begin{array}{l}\text { No of } \\
\text { patients }\end{array}$ & Duration & $\begin{array}{l}\text { Study arms } \\
\text { tocilizumab in } \\
\mathrm{mg} / \mathrm{kg} / 4 \text { weeks }\end{array}$ & ACR20 & ACR50 & ACR70 & DAS28 $<2.6$ \\
\hline \multirow[t]{4}{*}{ CHARISMA } & Maini et a ${ }^{137}$ & R-DB-PC & 359 & $16 w k$ & $0+m t x$ & 41 & 29 & 8 & - \\
\hline & & & & & $2 / 2+m t x$ & $31 / 64$ & $6 / 32$ & $2 / 14$ & - \\
\hline & & & & & $4 / 4+m t x$ & $61 / 63$ & $28 / 37$ & $6 / 12$ & - \\
\hline & & & & & $8 / 8+m t x$ & $63 / 74$ & $4 I / 53$ & $16 / 37$ & - \\
\hline \multirow[t]{3}{*}{ OPTION } & Smolen et $\mathrm{a}^{38}$ & R-DB-PC & 623 & $24 w k$ & $0+m t x$ & 26 & 11 & 2 & 0.8 \\
\hline & & & & & $4+m t x$ & 48 & 31 & 12 & 13 \\
\hline & & & & & $8+m t x$ & 59 & 44 & 22 & 27 \\
\hline \multirow[t]{2}{*}{ TOWARD } & Genovese et $\mathrm{a}^{39}$ & R-DB-PC & 1220 & $24 w k$ & $0+$ DMARD & 25 & 9 & 3 & 3 \\
\hline & & & & & $8+$ DMARD & 61 & 38 & 21 & 30 \\
\hline \multirow[t]{3}{*}{ RADIATE } & Emery et $\mathrm{al}^{40}$ & R-DB-PC & 499 & & $0+m t x$ & 10 & 4 & 1.3 & 1.6 \\
\hline & & & & & $4+m t x$ & 30 & 17 & 5 & 7.6 \\
\hline & & & & & $8+m t x$ & 50 & 29 & 12.4 & 30.1 \\
\hline \multirow[t]{2}{*}{ SATORI } & Nishimoto et $\mathrm{a}^{41}$ & R-DB-PC & 125 & $24 w k$ & placebo $+m t x$ & 25 & 10.9 & 6.3 & 1.6 \\
\hline & & & & & toc $8+$ placebo & 80.3 & 49.2 & 29.5 & 43.1 \\
\hline
\end{tabular}

Abbreviations: ACR, American College of Rheumatology; DAS, Disease Activity Score; DMARD, disease-modifying antirheumatic drug; mtx, methotrexate; R-DB-PC, randomized, double-blind, placebo-controlled.

Yokota and colleagues ${ }^{43}$ evaluated the safety and efficacy of tocilizumab in a dose-escalating protocol (MRA011JP) in 11 Japanese children (3-18 years) with active systemic onset JIA refractory to corticosteroids and/or DMARDs. Primarily Yokota and colleagues infused a $2 \mathrm{mg} / \mathrm{kg} /$ dose three times with a two-week interval. The dose was increased to $4 \mathrm{mg} / \mathrm{kg}$ and administered three times if CRP level were above $1.5 \mathrm{mg} / \mathrm{dl}$ after the first and second infusion and further to $8 \mathrm{mg} / \mathrm{kg}$ three times if CRP was still above $1.5 \mathrm{mg} / \mathrm{dL}$. Tocilizumab abruptly reduced disease activity in 10 of the 11 children two weeks after the administration of the drug. Three children had sustained response to $2 \mathrm{mg} / \mathrm{kg}$, five of the remaining eight children were stabilized with $4 \mathrm{mg} / \mathrm{kg}$, and three children received $8 \mathrm{mg} / \mathrm{kg}$ before CRP was kept below $1.5 \mathrm{mg} / \mathrm{dL}$. In total, ACRPed30 and ACRPed50 was achieved in 10 children and ACRPed70 was achieved in seven children.

In another open-labelled trial (LRO320), 15 of 18 enrolled Caucasian children with systemic JIA received a single dose of either $2 \mathrm{mg} / \mathrm{kg}(\mathrm{n}=4), 4 \mathrm{mg} / \mathrm{kg}(\mathrm{n}=6)$, or $8 \mathrm{mg} / \mathrm{kg}(\mathrm{n}=5)$ tocilizumab by infusion. ${ }^{44}$ All had active disease for at least three months with at least one active systemic feature, one active joint, and prednisolone doses above $0.2 \mathrm{mg} / \mathrm{kg} /$ day and in addition 12 also received methotrexate $\left(<20 \mathrm{mg} / \mathrm{m}^{2} /\right.$ week $)$. Although only a small number of patients were studied, there was a marked improvement in all patients within all three dose groups 48 hours after the infusion and at one-week follow-up, 11 patients achieved ACRPed30, eight patients achieved ACRPed50, and three achieved ACRPed70.
However, a prolonged clinical response was only observed for $4 \mathrm{mg} / \mathrm{kg}$ and $8 \mathrm{mg} / \mathrm{kg}$ with an ACRPed30 obtained in $6 / 9$ patients. Along with the clinical improvement, a marked decrease in CRP and ESR after one week was followed by an increase shortly after.

While writing this review, only one randomized doubleblind, placebo-controlled withdrawal study (MRA316JP) of the effect of tocilizumab for the treatment of Japanese children with systemic JIA has been published. ${ }^{45}$ The study included an open-label lead-in phase of six weeks, a double-blind, randomized, placebo-controlled withdrawal phase of 12 weeks, and an open-label extension phase of 48 weeks or more. Fifty-six children ( 21 boys, 35 girls) with active systemic JIA defined by an increase in CRP $>15 \mathrm{mg} / \mathrm{L}$ and inadequate clinical response to $\geq 0.2 \mathrm{mg} / \mathrm{kg} /$ day of prednisolone were enrolled in the open-label lead-in phase. They received $8 \mathrm{mg} / \mathrm{kg}$ tocilizumab three times every two weeks with a primary endpoint being ACRPed30 (Table 3). After six weeks, ACRPed30, 50, and 70 was achieved in $91 \%, 86 \%$, and $68 \%$, respectively. Forty-three patients continued to the double-blind withdrawal phase and were randomly assigned to either receive an infusion of tocilizumab $8 \mathrm{mg} / \mathrm{kg}$ or placebo every two weeks for 12 weeks. In the tocilizumab group $80 \%$ maintained an ACRPed30 or ACRPed50 response and a CRP concentration $<15 \mathrm{mg} / \mathrm{l}$ after 12 weeks compared to $17 \%$ in the placebo group ( $p<0.0001$ ) (Table 4). Half of the children in the placebo group who did not maintain ACRPed30 relapsed within four weeks. In the open-labeled extension phase, 48 of the 
Table 3 Response to tocilizumab $8 \mathrm{mg} / \mathrm{kg}$ every two weeks in patients with systemic onset juvenile idiopathic arthritis in a six week open-label lead-in phase ${ }^{45}$

\begin{tabular}{ll}
\hline & Number of pts. (\%) \\
\hline ACRPed30 & $51 / 56(91 \%)$ \\
ACRPed50 & $48 / 56(86 \%)$ \\
ACRPed70 & $38 / 56(68 \%)$ \\
\hline
\end{tabular}

Abbreviation: ACRPed, American College of Rheumatology Pediatric criteria.

50 patients continued to receive tocilizumab after 48 weeks. Achievement of ACRPed 30, 50, and 70 was observed in 98\%, $94 \%$, and $90 \%$, respectively. The median percentage change in ESR and CRP was $-93.2 \%$ and $-99.7 \%$, respectively, along with a significant increase in hemoglobin.

In 2008, an ongoing two-part phase III multicenter study (WA18221) consisting of a part I 12-week randomized, double-blind, placebo-controlled two-arm study evaluating the efficacy and safety of tocilizumab in patients with systemic JIA was launched with a subsequent part II 92-week singlearm open-label extension study to examine the long-term use of tocilizumab. Pediatric rheumatology centers from Europe, North America, and South America are participating in the study. The patients are randomized to either $8 \mathrm{mg} / \mathrm{kg}$ for patients $>30 \mathrm{~kg}$ every two weeks and $12 \mathrm{mg} / \mathrm{kg}$ for patients $<30 \mathrm{~kg}$ or placebo infusions every two weeks. The patients $(\mathrm{n}=108)$ are unequally randomized (tocilizumab/placebo ratio 2:1). The primary efficacy endpoints are the proportion of patients with at least 30\% improvement in JIA core set (ACRPed30) at week 12 and absence of fever. The rationale for using the increased dose $(12 \mathrm{mg} / \mathrm{kg})$ for small children $<30 \mathrm{~kg}$ was chosen as a consequence of the pharmacokinetic, safety, and efficacy data from the MRA316JP study.

\section{Clinical efficacy in oligo- and polyarticular onset JIA}

In a case report, a 26-year-old woman with oligoarthritis for 12 years was described having developed amyloidosis in the kidney and intestines. The patient responded well to the

Table 4 Maintained ACRPed response after a I2-week double-blind phase continuing with either tocilizumab $8 \mathrm{mg} / \mathrm{kg}$ every two weeks or placebo ${ }^{45}$

\begin{tabular}{llll}
\hline & Tocilizumab & Placebo & P value \\
\hline ACRPed30 & $16 / 20(80 \%)$ & $4 / 23(17 \%)$ & $\mathrm{P}<0.0001$ \\
ACRPed50 & $16 / 20(80 \%)$ & $4 / 23(17 \%)$ & $\mathrm{P}<0.0001$ \\
ACRPed70 & $15 / 20(75 \%)$ & $3 / 23(13 \%)$ & $\mathrm{P}<0.0001$ \\
\hline
\end{tabular}

Abbreviation: ACRPed, American College of Rheumatology Pediatric criteria. treatment of intravenous $8 \mathrm{mg} / \mathrm{kg}$ tocilizumab given every 3-4 weeks. ${ }^{46}$

One prospective, open-labeled, multicenter study has been performed in patients with polyarticular or oligoarticular onset JIA with a polyarticular course. ${ }^{47}$ The children were treated with $8 \mathrm{mg} / \mathrm{kg}$ tocilizumab every four weeks for 48 weeks. Concomitant treatments with other biologics, DMARDs, or immunosuppressants were not allowed. Nineteen patients were enrolled in the study with the primary efficacy endpoint being the proportion of patients achieving ACRPed30, 50, and 70 every 12 weeks from the baseline evaluation. They found a significant decrease in all core set parameters with an ACRPed30 of $94.1 \%$ after 12 weeks. The response continued until the evaluation after 48 weeks where 11 completed the assessments (ACRPed30, 100\%; ACRPed50, 100\%; ACRPed70, 90.9\%).

\section{Safety and tolerability}

In the phase II study, Yokota and colleagues, ${ }^{43}$ reported that the drug was generally well tolerated at all doses. Two patients had upper respiratory tract infections and three had pustules on the extremities. In four patients, cholesterol increases were observed, two patients showed elevated alanine aminotransferases, and two showed glucosuria. Woo and colleagues ${ }^{44}$ reported no evidence of dose-limiting toxicity. Fifty-nine adverse events were reported in 15 patients with mainly gastroenteritis and respiratory disorders. Three had elevated alanine aminotransferases and one had urticaria. No serious bacterial infections were seen.

Two serious adverse events were reported in in the lead-in phase of the phase III study (MRA316JP): $:{ }^{45}$ one with anaphylaxis and one with gastrointestinal hemorrhage from colonic ulceration in a patient with previous history of diarrhea and rectal bleeding. In the double-blind phase, one patient had infectious mononucleosis with highly elevated liver transaminases and neutropenia and one developed herpes zoster.

To evaluate the long-term safety of tocilizumab, 128 patients with systemic JIA including patients who completed the MRA011JP and MRA316JP studies and an additional 61 patients were enrolled. ${ }^{48}$ Tocilizumab was administered as an infusion of $8 \mathrm{mg} / \mathrm{kg}$ every two weeks. The median duration of tocilizumab treatment was 78 weeks. Adverse events occurred in 120 patients (94\%) at a rate of 787 per 100 patientyears. Serious adverse events occurred at an incidence rate of 37.2 per 100 patient years and serious infections at a rate of 14.5 per patients-years. The most frequent serious 
infections were gastroenteritis (3.8/100 patient-years) and pneumonia (3.4/100 patient-years). In total, 14 patients were withdrawn from the study. Eight patients were withdrawn from the study due to adverse events which included macrophage activation syndrome, anaphylactoid reaction (two patients), cardiac amyloidosis, duodenal perforation, gastrointestinal hemorrhage, and infusion reactions (two patients). Furthermore, five patients were withdrawn from the study due to the development of antitocilizumab antibodies and one due to lack of efficacy.

\section{Place in therapy for tocilizumab in JIA}

With the advent of biological response modifiers, commonly referred to as biologics, the therapeutical options for JIA have improved considerably. The use of TNF $\alpha$ inhibitors for the treatment of JIA with a polyarticular course refractory to conventional methotrexate has shown efficacy in controlled clinical trials with etanercept, infliximab, and adalimumab. ${ }^{49}$ A long-term follow-up study with etanercept has shown a sustained effect and with relatively few serious adverse events and high tolerability. ${ }^{50}$

However, children with systemic onset JIA may often be refractory to treatment with both conventional DMARDs and biologics. Response rates as low as 30\% using etanercept have been shown ${ }^{23}$ and often unacceptably high doses of corticosteroids are used to control the disease. Only one phase III double-blind placebo-controlled withdrawal study with tocilizumab has been published so far in systemic JIA. ${ }^{45}$

The study design, combining an open-label lead-in phase with a placebo-controlled withdrawal phase, has been used for studying biologics in JIA randomized controlled trials for the last decade and is considered ethically acceptable for the use in children. Tocilizumab infusions of $8 \mathrm{mg} / \mathrm{kg}$ every other week achieved high response rates with an ACRPed50 of $86 \%$. Compared to this, tocilizumab $8 \mathrm{mg} / \mathrm{kg}$ given every four weeks to adult patients with RA resulted in an ACR50 of 29\%-49\% in four phase III studies.

Response to tocilizumab therapy is seen with few weeks and even days. The drug is generally well tolerated with an incidence of serious adverse events of 37/100 patient-year. The most frequent serious infections are gastroenteritis and pneumonia, at 3.8 and 3.4/100 patient-years, respectively.

If the ongoing double-blind placebo-controlled tocilizumab randomized controlled trial (WA18221) for systemic JIA shows comparable results as in the Japanese study, tocilizumab could be considered as a first-line drug in corticosteroid-resistant systemic JIA.
However, direct comparison of treatment with tocilizumab and TNF $\alpha$-inhibitors or other biologics like abatacept or IL-1R inhibitors in head-to-head or crossover studies could be warranted to elucidate its role in the therapeutic option of systemic JIA.

There is still very limited information regarding the pharmacoeconomic aspects of the treatment of children with JIA with tocilizumab.

In summary, tocilizumab is an effective drug for the treatment of systemic onset JIA. It represents an interesting option for patients refractory to or dependent on corticosteroid therapy. Full data are not yet available to place its role in the treatment of nonsystemic JIA where other biologics have shown a higher efficacy. However, the significant effect on adult RA may indicate that tocilizumab could also have a promising role for polyarticular JIA.

\section{Disclosure}

The author reports no conflicts of interest in this work.

\section{References}

1. Petty RE, Southwood TR, Manners P, et al. International League of Associations for Rheumatology classification of juvenile idiopathic arthritis: second revision, Edmonton 2001. J Rheumatol. 2004;31(2):390-392.

2. Berntson L, Andersson Gäre B, Fasth A, et al. Incidence of juvenile idiopathic arthritis in the Nordic countries. A population based study with special reference to the validity of the ILAR and EULAR criteria. Nordic Study Group. J Rheumatol. 2003;30(10):2275-2282.

3. Riise ØR, Handeland $\mathrm{KS}$, Cvancarova $\mathrm{M}$, et al. Incidence and characteristics of arthritis in Norwegian children: A population-based study. Pediatrics. 2008;121(2):e299-e306.

4. Woo P. Systemic juvenile idiopathic arthritis: Diagnosis, management and outcome. Nat Clin Pract Rheumatol. 2006;2:28-34.

5. Lomater C, Gerloni V, Gattinara M, et al. Systemic onset juvenile idiopathic arthritis: A retrospective study of 80 consecutive patients followed for 10 years. J Rheumatol. 2000;27:491-496.

6. Ravelli A, Magni-Manzoni S, Pistorio A, et al. Preliminary diagnostic guidelines for macrophage activation syndrome complicating systemic juvenile idiopathic arthritis. J Pediatr. 2005;146(5):598-604.

7. Wolvekamp MC, Marquet RL. Interleukin-6: historical background, genetics and biological significance. Immunol Lett. 1990;24:1-9.

8. Murakami M, Hibi M, Nakagawa N, et al. IL-6 induced homodimerization of gp130 and associated activation of a tyrosine kinase. Science. 1993;260:1808-1810.

9. Heinrich PC, Behrmann I, Muller-Newen G, Schaper F, Graeve L. Interleukin-6-type cytokine signalling through the gp130/Jak/STAT pathway. Biochem J. 1998;334:297-314.

10. De Benedetti F, Massa M, Robbioni P, Ravelli A, Burgio GR, Martini A. Correlation of serum interleukin-6 levels with joint involvement and thrombocytosis in systemic juvenile rheumatoid arthritis. Arthritis Rheum. 1991;34(9):1158-1163.

11. Lepore L, Pennesi M, Saletta S, Perticarari S, Presani G, Prodan M. Study of IL-2, IL-6, TNF alpha, IFN gamma and beta in the serum and synovial fluid of patients with juvenile chronic arthritis. Clin Exp Rheumatol. 1994;12(5):561-565.

12. Rooney M, David J, Symons J, Di Giovine F, Varsani H, Woo P. Inflammatory cytokine responses in juvenile chronic arthritis. $\mathrm{Br} J$ Rheumatol. 1995;34(5):454-460. 
13. Mangge H, Kenzian H, Gallistl S, et al. Serum cytokines in juvenile rheumatoid arthritis. Correlation with conventional inflammation parameters and clinical subtypes. Arthritis Rheum. 1995;38(2):211-220.

14. De Benedetti F, Martini A. Is systemic juvenile rheumatoid arthritis an interleukin 6 mediated disease? J Rheumatol. 1998;25(2):203-207.

15. De Benedetti F, Pignatti P, Massa M, et al. Circulating levels of interleukin 1 beta and of interleukin receptor antagonist in systemic juvenile chronic arthritis. Clin Exp Rheumatol. 1995;13:779-784.

16. Keul R, Heinrich PC, Müller-Newen G, Müller K, Woo P. A possible role for soluble IL-6 receptor in the pathogenesis of systemic onset juvenile chronic arthritis. Cytokine 1998;10(9):729-734.

17. Fishman D, Faulds G, Jeffery R, et al. The effect of novel polymorphisms in the interleukin-6 (IL-6) gene on IL-6 transcription and plasma IL-6 levels, and an association with systemic-onset juvenile chronic arthritis. J Clin Invest. 1998;102:1369-1376.

18. Ogilvie EM, Fife MS, Thompson SD, et al. The $-174 \mathrm{G}$ allele of the interleukin-6 gene confers susceptibility to systemic arthritis in children: a multicenter study using simplex and multiplex juvenile idiopathic arthritis families. Arthritis Rheum. 2003;48:1398-1407.

19. Giannini EH, Ruperto N, Ravelli A, Lovell DJ, Felson DT, Martini A. Preliminary definition of improvement in juvenile arthritis. Arthritis Rheum. 1997;40:1202-1209.

20. Klein-Gitelman MS, Pachman LM. Intravenous corticosteroids: adverse reactions are more variable than expected in children. J Rheumatol. 1998;25:1995-2002.

21. Woo P, Southwood TR, Prieur AM, et al. Randomised placebo-controlled crossover trial of low-dose oral methotrexate in children with extended oligoarticular or systemic arthritis. Arthritis Rheum. 2000;43: 1849-1857.

22. Quartier P, Taupin P, Bourdeaut F, et al. Efficacy of etanercept for the treatment of juvenile idiopathic arthritis according to the onset type. Arthritis Rheum. 2003;48:1093-1101.

23. Kimura Y, Pinho P, Walco G, et al. Etanercept treatment in patients with refractory systemic onset juvenile rheumatoid arthritis. J Rheumatol. 2005;32:935-942.

24. Pascual V, Allantaz F, Arce E, et al. Role of interleukin-1 (IL-1) in the pathogenesis of systemic onset juvenile idiopathic arthritis and clinical response to IL-1 blockade. J Exp Med. 2005;201(9):1479-1486.

25. Lequerré T, Quartier P, Rosellini D, et al. Interleukin-1 receptor antagonist (anakinra) treatment in patients with systemic-onset juvenile idiopathic arthritis or adult onset Still disease: preliminary experience in France. Ann Rheum Dis. 2008;67(3):302-308.

26. Quartier P, Allantaz F, Cimaz R, et al. A multicentre, double-blind trial of Anakinra versus placebo in systemic-onset juvenile idiopathic arthritis (ANAJIS trial): efficacy and tolerance over 12 months. Arthritis Rheum. 2008;58(9)Supplement:S632.

27. Lovell DJ, Giannini EH, Kimura Y, et al. Preliminary evidence for sustained bioactivity of IL-1 Trap (rilonacept), a long acting IL-1 inhibitor, in systemic juvenile idiopathic arthritis (SJIA). Arthritis Rheum. 2007;56:S514

28. Van Zaanen HC, Lokhorst HM, Aarden LA, Rensink HJ, Warnaar SO, van Oers MH. Chimaeric anti-interleukin-6 monoclonal antibodies in the treatment of advanced multiple myeloma: a phase I dose-escalating study. Br J Haematol. 1998;102:783-790.

29. Durandy A. Anti-B cell and anti-cytokine therapy for the treatment of post-transplant lymphoproliferative disorder: past, present and future. Transpl Infect Dis. 2001;3:104-107.

30. Sato K, Tsuchiya M, Sladanha J, Koishihara Y, Ohsugi Y, Kishimoto T. Reshaping a human antibody to inhibit the interleukin-6-dependent tumor cell growth. Cancer Res. 1993;53:851-856.

31. Takagi N, Mihara M, Moriya Y, et al. Blockage of interleukin-6 receptor ameliorates joint disease in murine collagen-induced arthritis. Arthritis Rheum. 1998;41(12):2117-2121.

32. Yoshizaki K, Kishimoto T. Therapy of rheumatoid arthritis by blocking IL-6 signal transduction with a humanized anti-IL-6 receptor antibody. Springer Semin Immunopathol. 1998;20(1-2):247-259.
33. Nishimoto N, Kishimoto T, Yoshizaki K. Anti-interleukin-6 receptor antibody treatment in rheumatic disease. Ann Rheum Dis. 2000; 59(Suppl 1):i21-i27.

34. Choy EH, Isenberg DA, Garrood T, et al. Therapeutic benefit of blocking interleukin-6 activity with an anti-interleukin-6 receptor monoclonal antibody in rheumatoid arthritis: a randomized, double-blind, placebo-controlled, dose-escalation trial. Arthritis Rheum. 2002;46(12):3143-3150.

35. Nishimoto N, Sasai M, Shima Y, et al. Improvement in Castleman's disease by humanized anti-interleukin- 6 receptor antibody therapy. Blood. 2000; 95(1):56-61.

36. Iwamoto M, Nara H, Hirata D, Minota S, Nishimoto N, Yoshizaki K. Humanized monoclonal anti-interleukin-6 receptor antibody for treatment of intractable adult-onset Still's disease. Arthritis Rheum. 2002;46(12):3388-3389.

37. Maini RN, Taylor PC, Szechinski J, et al; CHARISMA Study Group. Double-blind randomized controlled clinical trial of the interleukin-6 receptor antagonist, tocilizumab, in European patients with rheumatoid arthritis who had an incomplete response to methotrexate. Arthritis Rheum. 2006;54(9):2817-2829.

38. Smolen JS, Beaulieu A, Rubbert-Roth A, et al; OPTION Investigators. Effect of interleukin-6 receptor inhibition with tocilizumab in patients with rheumatoid arthritis (OPTION study): a double-blind, placebocontrolled, randomised trial. Lancet. 2008;371(9617):987-997.

39. Genovese MC, McKay JD, Nasonov EL, et al. Interleukin-6 receptor inhibition with tocilizumab reduces disease activity in rheumatoid arthritis with inadequate response to disease-modifying antirheumatic drugs: the tocilizumab in combination with traditional diseasemodifying antirheumatic drug therapy study. Arthritis Rheum. 2008; 58(10):2968-2980.

40. Emery P, Keystone E, Tony HP, et al. IL-6 receptor inhibition with tocilizumab improves treatment outcomes in patients with rheumatoid arthritis refractory to anti-tumour necrosis factor biologicals: results from a 24-week multicentre randomised placebo-controlled trial. Ann Rheum Dis. 2008;67(11):1516-1523.

41. Nishimoto N, Miyasaka N, Yamamoto K, et al. Study of active controlled tocilizumab monotherapy for rheumatoid arthritis patients with an inadequate response to methotrexate (SATORI): significant reduction in disease activity and serum vascular endothelial growth factor by IL-6 receptor inhibition therapy. Mod Rheumatol. 2009;19(1):12-19.

42. Nishimoto N, Hashimoto J, Miyasaka N, et al. Study of active controlled monotherapy used for rheumatoid arthritis, an IL-6 inhibitor (SAMURAI): evidence of clinical and radiographic benefit from an $\mathrm{x}$ ray reader-blinded randomised controlled trial of tocilizumab. Ann Rheum Dis. 2007;66(9):1162-1167.

43. Yokota S, Miyamae T, Imagawa T, et al. Therapeutic efficacy of humanized recombinant anti-interleukin-6 receptor antibody in children with systemic-onset juvenile idiopathic arthritis. Arthritis Rheum. 2005;52(3):818-825.

44. Woo P, Wilkinson N, Prieur AM, et al. Open label phase II trial of single, ascending doses of MRA in Caucasian children with severe systemic juvenile idiopathic arthritis: proof of principle of the efficacy of IL-6 receptor blockade in this type of arthritis and demonstration of prolonged clinical improvement. Arthritis Res Ther. 2005;7(6): R1281-R1288.

45. Yokota S, Imagawa T, Mori M, et al. Efficacy and safety of tocilizumab in patients with systemic-onset juvenile idiopathic arthritis: a randomised, double-blind, placebo-controlled, withdrawal phase III trial. Lancet. 2008;371(9617):998-1006.

46. Okuda Y, Takasugi K. Successful use of a humanized antiinterlukin-6 receptor antibody, tocilizumab, to treat amyloid A amyloidosis complicating juvenile idiopathic arthritis. Arthritis Rheum. 2006;54:2997-3000.

47. Imagawa T, Ozawa R, Miyamae T, et al. Efficacy and safety in 48-week treatment of tocilizumab in children with polyarticular course juvenile idiopathic arthritis with polyarticular or oligoarticular onset. Ann Rheum Dis. 2007;66(Suppl II):550. 
48. Yokota S, Imagawa T, Miyamae T, et al. Long-term safety and efficacy of tozilizumab in patients with systemic juvenile idiopathic arthritis (JIA) under the extension and long-term trials. Arthritis Rheum. 2008; 58(9)Supplement:S631.

49. Ilowite NT. Update on biologics in juvenile idiopathic arthritis. Curr Opin Rheumatol. 2008;20:613-618.
50. Lovell DJ, Reiff A, Ilowite NT, et al. Safety and efficacy of up to eight years of continuous etanercept therapy in patients with juvenile rheumatoid arthritis. Arthritis Rheum. 2008;58(5):1496-1504.

\section{Core Evidence}

\section{Publish your work in this journal}

Core Evidence is an international, peer-reviewed open-access journal evaluating the evidence underlying the potential place in therapy of drugs throughout their development lifecycle from preclinical to postlaunch. The focus of each review is to evaluate the case for a new drug or class in outcome terms in specific indications and patient

Submit your manuscript here: http://www.dovepress.com/core-evidence-journal

\section{Dovepress}

groups. The manuscript management system is completely online and includes a very quick and fair peer-review system, which is all easy to use. Visit http://www.dovepress.com/testimonials.php to read real quotes from published authors. 